European Journal of Probation University of Bucharest www.ejprob.ro

Vol. 5, No.2, 2013, pp $47-65$ ISSN: $2006-2203$

\title{
Desistance by Design: Offenders' Reflections on Criminal Justice Theory, Policy and Practice
}

\author{
Monica Barry ${ }^{1}$
}

\begin{abstract}
This article highlights the views and advice of offenders in Scotland about what helps and hinders young people generally in the process of desistance, why interventions may or may not encourage desistance and what criminal justice and other agencies can do to alleviate the problems which may result in offending. The findings suggest that probation-style supervisory relationships with workers are still the key means to promote desistance but given the fact that offenders perceive desistance to be 'by design' rather than 'by default', there still needs to be a greater emphasis placed by criminal justice and wider agencies on the structural constraints to a legal, conventional and integrated lifestyle.
\end{abstract}

Key words: Criminal justice - desistance - interventions - prevention - probation.

\section{Introduction}

Rarely have young offenders been asked their advice on why young people desist from crime or what constitutes effective criminal justice policy and practice in promoting desistance. This article draws on a recent study of young offenders and ex-offenders views and experience of criminal justice interventions and desistance from crime. One innovative aspect of this study, and the focus of this article, was to ask young offenders questions which put them in the role of theorist ('why do you think young people stop offending?'), policy maker ('what can agencies do to help young people stop offending?'), and practitioner ('how would you help young people stop offending?'). This article therefore gives precedence to their verbatim answers to these types of questions, drawn from two tranches of interviews with offenders over a ten year period in Scotland.

\footnotetext{
${ }^{1}$ Senior Research Fellow, Centre for Law, Crime and Justice, School of Law, University of Strathclyde, Room 737b, Graham Hills Building, 50 George Street, Glasgow, G1 1BA. Tel: 01415482745 E-mail: monica.barry@strath.ac.uk
} 
Many studies of desistance draw on the experiences of primarily current offenders subject to criminal justice interventions, in particular probation and imprisonment (Burnett, 1992; Farrall, 2002; Healy, 2010; Maruna, 2001; Rex, 1999) to explore why and how they desist from crime. Others find current and ex-offenders from within their own communities, often after rather than during criminal justice involvement, to explore their narratives about the dynamics of circumstances, power, age and relationships in the process of becoming lawabiding (Barry, 2006; Sampson and Laub, 1993; Weaver, 2012). Despite the potential significance of where and when offenders are accessed for research purposes, however, the currently ascendant desistance theories tend to be subsumed under three key headings: 'subjective, 'structural and 'integrative', all of which to a greater or lesser extent use the narratives of offenders themselves to inform a greater understanding of the process of desistance (Vaughan, 2007).

Subjective theories of desistance focus on age, attitudes and personal characteristics of desisters - whether the inevitability of maturation (Gottfredson and Hirschi, 1990; Rutherford, 1986), or as a result of 'burn out', the deterrent effect of the criminal justice system or cognitive changes in attitude or identity (Farrall, 2002; Giordano et al, 2002; Maruna, 2001), relational dynamics (Weaver, 2012) and/or a reassessment of the costs and benefits of crime (Cornish and Clarke, 1985). Maruna (2001) focuses on offenders' selfidentity and their use of 'redemption scripts' to enable and permit them to break with their past identities and to forge new ones, but acknowledges the possibility that without adequate social supports in their immediate milieu, good motives and personal determination alone will be insufficient to effect change. The significance of power imbalances and the liminal nature of youth in the transition to adulthood are under-theorised, however, despite the fact that the political, economic and social impact of an increasingly prolonged transition to adulthood characteristic of modern times is seen as highly relevant to understanding offending and desistance in young people in particular (Barry, 2006).

Structural theories of desistance emphasise the role of informal social bonds or controls such as relationships, employment and marriage - in fostering individual compliance with the law. Hirschi's control theory (1969) characterised 'social bonds' as emotional ties to others, investment in relationships, access to legitimate activities, and normative commitment to the rule of law, but his theory stresses that it is the quality rather than merely the formal reality of such bonds that is important in encouraging desistance (Laub and Sampson, 2003). Sampson and Laub (1993) suggest that structural turning points - 'exogenous' events such as marriage, employment or military service - almost by default encourage desistance. But such social control theories have been criticised for being overly structural and not including agency (i.e., motivation to change) (Bottoms and Shapland, 2011), and Laub and Sampson (2003) have more recently refined their theory of social bonds to include more subjective elements such as commitment, personal investment and motivation, but it nevertheless remains controversial (LeBel et al, 2008), partly because of the lack of agency afforded would-be desisters.

Integrative theories of desistance bring together subjective and structural influences to bear on the process of desistance in a more sociologically oriented way, emphasising how personal life events and strengthened resolve and motivation on the part of an offending individual 
must necessarily mesh with (even precede) available social resources to facilitate the giving up of crime (Giordano et al, 2002; LeBel et al, 2008; Morizot and Le Blanc, 2007; Vaughan, 2007). Giordano et al (2002) stress the importance of cognitive change, alternative identities and moral values, but alongside structural turning points or 'hooks for change' which the individual has to identify, select and act upon through 'cognitive transformations' (Bottoms and Shapland, 2011). The concept of capital, as conceptualised by Bourdieu (1986), which combines agency and structure to varying degrees depending on how the concept is appropriated, has also become integral to understanding the desistance process, notably in terms of links to employers, the availability (or otherwise) of helping agencies and support networks (both informal and professional) beyond the immediate family circle (Braithwaite 1989; Farrall, 2002; Weaver and McNeill, 2010), and the motivation and encouragement of individuals in accumulating and investing in such capital (Barry, 2006, 2007). Such theories usually incorporate strengths-based notions of offender rehabilitation, rightly crediting offenders with the capacity to develop social skills and to use their innate abilities to create change, but not intending to prioritise, as overly subjective theories of desistance might do, the transcendent potency of agency in giving up crime.

\section{The Scottish Desistance Study}

The original study on which these findings are based was undertaken in 2000 and involved in-depth interviews with 40 young people aged 18-33. The aim of that original study was primarily to explore young offenders' reasons for starting and stopping offending and their views and experiences of desistance. The sample was identified through a third sector organisation in Scotland offering Government-funded intensive probation programmes to persistent young adult offenders under the age of 25 . Staff contacted by letter a random sample of ex-clients who had $3+$ previous convictions and who had been on intensive probation at least 2 years prior to this approach. In 2010, with funding from the Economic and Social Research Council (grant reference number RES-061-30-000156), a follow up study of those offenders from ten years ago was undertaken and matched with a new sample of younger offenders/ex-offenders. Whilst wider findings from these two combined studies are being published elsewhere, this article focuses in particular on these samples' advice on what helps and hinders the desistance process for young people, not only in respect of their own attitudes and circumstances but also in respect of wider policy and practice.

In 2010, I traced as many of those original respondents as I could, and managed to interview exactly half of them again -11 men and 9 women, now aged 29-43. Of the 20 young people who could not be traced again, 3 were known to have died; 2 did not want to be reinterviewed; and 15 had simply disappeared from the radar. To supplement this sub-sample, I also interviewed a 'new' sample of 20 young people aged 21-33, who were recruited from the same sources and using the same criteria as the original sample 10 years previously, namely, young people aged 18-30 with 3+ previous convictions and subject to intensive probation prior to the age of 25 . The original sample had an average of 35 previous convictions, and their offending histories had lasted on average 13 years to date. Their offences were primarily theft, assault and drug-related violent and acquisitive crimes. The majority of the original follow-up interviews - 17 out of 20 interviews - took place in the respondents' homes, and the 
other three took place in a social work office, in prison and in a homeless hostel. The interviews averaged 94 minutes in length, varying from 65 to 135 minutes long. The new sample - 12 men and 8 women - had an average of 30 previous convictions and their offending histories had lasted on average 7 years to date. Ten of the new sample were interviewed in their own homes, six in prison, two in social work offices, one in hospital and one in a car. The interviews averaged 66 minutes in length, in the range 30 to 120 minutes long.

The so-called 'zig-zag' path to desistance is evident in both the original and new samples' movement between primary and secondary desistance (Healy, 2010; King, 2012), although most notably for the original sample whose path to desistance could be tracked over a 10 year period in early adulthood. For the original sample in 2000, there were 14 self-reported desisters and in the intervening 10 years, 8 of these people went back to offending and 6 had since stopped before the second interview in 2010. For the new sample in 2010, there were 14 self-reported desisters.

Before exploring the perceptions and advice of these respondents about what helps and hinders the desistance process in others, a brief summary is made here of their perceptions of why they themselves stopped offending. To stop offending, most implied that the process was what I would call 'desistance by design' (negotiated) rather than 'desistance by default' (coincidental). In other words they had to consciously give up the benefits of offending (status, money, friendships, excitement) in order to a) avoid further involvement with the criminal justice system and b) renew valued relationships with their parents, partners and children. Potential or actual commitments to significant family members was the primary reason for desistance amongst both samples, although interestingly and contrary to assumed gendered priorities, in the new sample of younger people, a commitment to family was more prevalent amongst the younger male respondents than amongst their female counterparts. There was also a realisation amongst both samples as they got older that they could potentially lose those close relationships by continued offending.

Stopping or controlling drug use was also seen as essential to many, but it was the older (original sample) respondents who associated stopping offending more with controlling drug use, whereas the younger (new sample) respondents associated stopping offending more with support from probation, social work and their religion, and seemed less dependent on drugs towards the end of their criminal careers despite the fact that alcohol/drugs were a major factor in their starting offending. Although employment is seen as a key turning point in the desistance literature (see, for example, Laub and Sampson, 2003), it barely gets a mention by these 40 respondents, perhaps because they are more realistic than idealistic about their chances of full integration through employment in the current economic climate. However, as Shildrick et al (2012) illustrate through follow-up interviews over a decade or more, despite young people still maintaining a strong commitment to [anticipated] employment, they have remained in 'low-pay, no-pay' work cycles over the last couple of decades. 


\section{Young People's Perceptions of Desistance in Others}

It is unlikely that young people have been asked to comment in qualitative research on why other young people give up offending. Invariably the emphasis of criminological research to date has been on offenders' own experiences of offending and desistance, coupled with professional stakeholder hypotheses as to why young people might desist from crime. This aspect of the Scottish Desistance Study is therefore innovative and informative about service user-led policy and practice, and could go some way to promoting co-production of criminal justice policy and practice in the future (Weaver, 2011).

Crucially, most of these respondents across both samples felt that others were more likely to stop offending in anticipation of [wanting] something different happening, rather than as a result of [already having] something different happening. This has serious implications for policy and practice and indeed for the desistance literature, and will be revisited later in this article. For example, the most commonly cited reason why other young people might stop offending was because they wanted - or in a minority of cases already had - a better, 'normal' or fuller life in adulthood. Burnett alludes to this as 'wishful thinking' (2004: 157), although more from an internal inability to desist rather than because of external constraints. Many respondents implied that other young people had potential turning points rather than actual turning points in giving up crime, as they also did about their own reasons for stopping. This was particularly the case amongst the men who wanted rather than already had a normal life, a family and a job or house. Paternoster and Bushway (2009) suggest that 'wanting' is not enough for desistance to occur, and that an actual strategy needs to be in place, although they acknowledge that strategies on their own (without external opportunities being available) are unlikely guarantees of sustained desistance. Nevertheless, although little research has been done to date on potential rather than actual turning points, we do know that actual turning points can have a significant effect on offending and desistance. For example, Moloney et al. (2009) found a positive correlation between actual fatherhood and desistance in a sample of gang members from the US, but with the Scottish sample, many of the men spoke hypothetically about settling down with a partner and children, but had yet to experience first-hand this potential turning point. Similarly with employment - the theory is that employment helps turn one's life around (Sampson and Laub, 1993; Uggen, 2000), but none of the Scottish sample had personal experience of employment. Burnett (2004: 158) found that over two thirds of her sample of male property offenders had no employment prospects but half 'had plans for employment', suggesting the potential if not actual attraction that a job holds for would-be desisters. As in their own reasons for stopping, the new sample did not mention employment as a trigger to others stopping offending, although whether this was because of their own experiences of seeking employment was not clear. Likewise a house was not mentioned by the new sample as being an incentive for others to give up crime. Starting a family and fearing the consequences of offending (for example, custodial sentences, ill health from substance misuse, police harassment and stigma) were, however, uppermost in these respondents' minds when commenting on why they had, or wanted to, give up crime. 
The 10 year difference in age range between the original and new samples and between the 2 tranches of the original sample over time is evident in some of their suggestions as to why other young people might stop offending, more so than as to why they thought they themselves stopped offending. For example, the new sample did not mention the adverse consequences of offending as much as the original sample - the fear of jail or ill health from drug misuse, and likewise did not stress the hassle of being involved in the criminal justice system over time. But this is likely to be because the original sample had had 10 years longer to experience these hassles and fears, 10 years longer of involvement in the criminal justice system and 10 years more maturity and reflection to wish to instil such fears and feelings in other young people. Paternoster and Bushway (2009: 1119) distinguish between a positive and negative 'possible self', with the former being the ideal case scenario but with no real strategy in place to achieve it, and the latter being the worst case scenario and probably the stronger motivator to change:

Offenders do not initially think about leaving crime because they suddenly see the advantages of a conventional life, but rather because they begin to see, in more vivid detail than ever, the costs and disadvantages of their lives of crime.

Given that many offenders gain nothing - in the short term at least - from not offending, it is remarkable that they stop offending at all, despite fearing the negative 'possible self'. One of the respondents from the original sample elaborated on this when asked what the advantages were of not offending and he mirrors the statement above made by Paternoster and Bushway:

'Advantages' makes it sound that you get something for not offending. Life is life, you know what I mean. You can only lose your life if you offend, you don't gain anything from not offending, if you know what I mean... You can gain stuff from offending but if you don't offend, what do you actually gain? (Pete, 29, original sample, 2010/11).

Indeed, what $d o$ they gain from not offending? And yet they still stop. They give up good money from theft, they give up drugs without medical help, they stay indoors rather than going out and getting into trouble, and they start paying for essential items with their limited benefits rather than stealing them:

[I] sit here all day... and just play on my laptop or tidy up... take the dog for a walk... sitting about the house bored all the time and nothing to do (Carol, 38, original sample, 2010/11).

[When I was offending] I had as much clothes as I wanted... and the good make-up, everything. I'm having to buy it now... like paying $£ 10$ for mascara, which I think is ridiculous... and I actually bought a foundation that was $£ 7$. I cringed and I was sitting looking at it and thinking 'I could just lift that in my bag' but I thought 'no'. I bought it, paid for it, and that was it. It's horrible paying for toothpaste and shite (Helen, 20, original sample, 2000/01). 
I actually grudged like honest money, you know, and that was one of the reasons I stole, you know, so that my money was going on stuff that I thought was worth it, which was drink or drugs. And so if I was buying food, you know, I grudged it, I would be really buying the cheapest stuff and minimal stuff as well (Eilidh, 26, new sample).

Most of these young people gave up crime, or expected to give up crime, with no outside help other than immediate family support. Certainly, only a few felt that the formal support mechanisms that criminal justice and wider agencies should arguably provide were indeed available and meaningful to them. Although they spoke highly of probation, for example, in helping others give up crime, they did not have as encouraging a view of it at the time that they themselves experienced it. The following section highlights the key attitudes of these young people to criminal justice interventions that they personally experienced before going on to illustrate their advice on how best to intervene with other young people in trouble.

\section{Views and Experience of Criminal Justice Interventions}

Both samples - the original sample in 2000/01 and 2010/11, and the new sample in 2010/11 were asked about the disposals they had received post-prosecution in the past and what they thought about those interventions, in terms of their purpose and effectiveness in supporting desistance.

Despite a finding by Farrall and Calverley (2006) that offenders become more favourably disposed towards supervision over time, the original sample in the Scottish Desistance Study seemed hardly to change their views over the ten year period in respect of attitudes to all disposals (suggesting that there was no perceived improvement in those interventions during that time and that growing older did not influence their perceptions of effectiveness or otherwise). There was also little difference by gender or by status as persister or desister. Respondents either liked or disliked interventions over time or had mixed views, and although their views of different criminal justice disposals was not a key focus of this research, a resume of their comments on each type of disposal is given below.

\section{Fines}

Out of the 34 people who had experienced fines in the past, only 3 thought they had been a deterrent, whilst the majority suggested they did not or could not pay them. One young woman argued that they were counterproductive - to pay them, one had to steal money from elsewhere:

I've had a lot of fines... but I didn't pay, so they put us in [prison]... When you're a drug addict and you've got fines to pay, it's even harder, so you'll be offending a lot more. Even though you might get caught, you're still offending... because you need your money for your habit but you need your money to keep yourself out of prison as well (Sarah, 27, original sample, 2000/01). 
It has long been seen as unjust that fines are imposed irrespective of one's ability to pay (Munro and McNeill, 2010). Gelsthorpe (2007) has also noted that where the courts do differentiate between those who can and those who cannot pay, it is women in particular who are deemed the most inappropriate recipients of fines because of their greater financial responsibilities for children and lesser capacity for independent means. The men in the sample in particular were also of the opinion that it is easier, quicker and cheaper to agree to a custodial sentence rather than pay a fine.

\section{Community Service}

Twenty-two of the 40 respondents mentioned receiving a community service order in the past and only 2 of these thought it was a positive experience, because it offered them the discipline of getting up in the morning, having something constructive to do or being taught skills for future employment.

It helps people, especially people that aren't willing to work, know what I mean?... it gives you something to do, it makes you go out and do work... it's getting you out and it's making you do things (Charlie, 21, original sample, 2000/01).

Thirteen respondents mentioned that they did not turn up for community service or that when they did attend, it was a negative experience, often because of the relationship with the supervisor, the quality of the work undertaken in the community or the fact that many were struggling with substance misuse during much of their criminal justice system involvement and found it difficult to remember and keep appointments.

\section{Probation/Intensive probation}

Because all members of both samples were accessed via probation projects, all had experienced this disposal at some point in their lives, many on multiple occasions. Probation and intensive probation were considered by these respondents the most likely interventions to help them and others with practical and emotional problems and to encourage desistance from crime. Key traits in their supervisors were being non-judgemental, showing respect for clients and being committed to supporting them with problems.

They didn't judge you at all... They were there, they would listen to you... they give you every bit of advice they possibly can to show you what you're doing to people... and I think that's what kinda really hit me (Dylan, 20, new sample).

I wanted to prove to [probation officer] that I could be - cos he was good with us. He gave us a lot of chances and that, so I wanted to prove to him that I could do it (Ryan, 23, new sample).

They put time and effort into sitting talking to you and working or attempt to work out with you what was going on, why you were doing these things. Instead of just going 
'you're a naughty bugger for doing it', you know, they actually, they wanted to find the root of the problem rather than gloss over the top (Pete, 29, old sample, 2010/11).

Weaver and Armstrong (2011: 11) found that probationers value a personalised supervisory process: 'giving the individual attention on a one-to-one basis... and tailoring the intervention to those individual needs'. However, although the purpose of probation was considered sound, its delivery and effectiveness were not. Whilst 15 people only ever experienced probation as positive, a further 10 only ever experienced it as negative and 15 had mixed views of it, with several suggesting that if their probation officer had been different (more personable and engaging), they might have cooperated more with supervision. Probation supervision was often criticised for being repetitive or stating the obvious, and probation officers were often criticised for being tokenistic or untrustworthy.

You're only sometimes seeing them once a week and you never tell them the whole truth cos it gets written in a report to go to court, so you want to gloss everything over, if you know what I mean (Vic, 34, old sample, 2010/11).

We just didn't get on so I didn't even want to go cos I was thinking 'oh, I have to go in here' and it was just a horrible atmosphere and I couldn't tell her anything and stuff like that. So I just sat there and let her [the probation officer] speak and she's like that 'you'll need to speak to us'. And I was like that 'but I don't feel comfortable speaking to you, so can I not change my worker?' And she went 'no, you'll just stick with me'. So then I ended up just saying 'fuck it, I'm not going' and breached it, got the jail. (Emma, 26, new sample).

\section{Custody}

Three quarters of the sample (30 respondents) had been in custody in the past, either on remand or sentence, and this high number experiencing custody was in keeping with the fact that the vast majority of the sample overall were high tariff offenders over a long period of time. Of these 30 people with experience of custody, 19 were predominantly negative about it, and 3 had mixed feelings:

It's just your freedom you lose when you go to prison, that's all it is. So I don't know. It wasn't a deterrent or that to me, you know. It wasn't' (Tom, 29, old sample, 2010/11).

The jail never gave me a fright. When I walked in, I had 4 uncles in, so when the visit came on, it was like a family reunion! (Vic, 34, old sample, 2010/11).

Of those who were negative, the main criticisms were that it taught you to become more criminally-minded or that it did not address the problems facing young people that were manifest in offending behaviour. One woman suggested that whilst prison might give you a fright, it is only a temporary deterrent, since nothing is done to address the issues for offenders on the outside: 
When I came back out, I came back out to a house full of addicts, so that wasn't a great start right away. My mother had buggered off with my son... so I wasn't seeing my mother, I wasn't seeing my son (Marie, 31, old sample, 2010/11).

Eight had something positive to say about imprisonment, in terms of its deterrent effect or time to reappraise one's situation, but also as a welcomed alternative to living in poverty in the community:

Jail was better than outside jail for me at the time, because I didn't pay rent, I had no bills to pay, I sat and I got all my meals, watched TV. Fair enough I was in my cell a lot but I could read, I could keep myself fit and that. So it was, being in jail was easy. To me, jail was an escape... It blinking makes folk want to go back half the time (Pete, 19, old sample, 2000/01).

Many of the respondents, mainly because of their high reconviction rates in the past, had experienced frequent and damaging periods of incarceration. Weaver and Armstrong (2011) suggest that constant periods of imprisonment, which can become a routine life activity, accumulate and amplify adverse impacts on offenders, not least in curtailing sustained opportunities for employment, family life and substance misuse treatment and creating feelings of hopelessness, anger and loss.

It was with this backdrop of their own experiences of interventions that these respondents could speak so fluently and knowledgeably about what they thought agencies could do to help young people stop offending, and how they themselves would help young people stop offending, and it is to this aspect of their knowledge base that we now turn.

\section{Addressing the Problem of Youth Offending}

When asked how they and agencies would address the problem of offending in youth, they either interpreted these questions in terms of 'interventions' after young people started offending or 'preventive approaches before young people started offending.In terms of interventions, communicating with young people on their level was seen as the most important means by which agencies could help young people stop offending. There was also a strong belief from these respondents that they themselves had much to offer other young offenders in terms of support and advice, again emphasising the importance of generativity in supporting the desistance process. The role of generativity, i.e., the commitment to care for others based on one's own experiences (Barry, 2006; Maruna, 2001), is a significant factor in the views of young offenders generally about what helps them and others to sustain a commitment to desistance. Roles as mothers, carers of ill parents, carers even of pets, a wish to educate younger people about the pitfalls of drugs and alcohol, are all roles that many offenders aspire to in the process of giving up crime and redeeming themselves (Maruna, 2001) in the eyes of others. Thus for these respondents, telling young people about the consequences of offending and about their own [adverse] experiences of the criminal justice system were important ways of preventing further offending. When talking about the consequences of offending, most of the respondents implied nipping it in the bud once it had 
started, rather than preventing it happening in the first place. In this regard, intensive probation was seen as a good thing because of its emphasis on programmes looking at the consequences of crime for offenders, their families and victims alike:

Show them who they're hurting like, and the effects that the crime can have on other people. I think that's important. I think that was probably the major thing that stopped me in my tracks, seeing like the effects it had on other people, cos I really didn't want to end up hurting other people and I didn't think about that at the time when I was offending (Dylan, 28, new sample).

Many suggested that a visit to, even a week's stay in, prison might deter young people from further offending, despite the majority speaking negatively about their own experience of prison. However, although some respondents thought a taste of imprisonment might deter young people from offending, wider research suggests otherwise - that it might make them worse - and the Scottish Government has also acknowledged this fact recently in its review of what works in reducing reoffending (Scottish Government, 2011). However, many of the young people thought prison was not as bad as it was made out to be and therefore was not a deterrent. Some suggested that in prison they could get 3 meals a day, play stations, see more of their extended family than they might on the outside, have seemingly easy access to drugs, and have a structured day. But these responses should not result in policy makers building prisons that are even less attractive to offenders, not least given the associated costs. The respondents also knew that prison, albeit relatively 'comfortable' compared with some of their own home circumstances, also had a deleterious effect on themselves and their peers and severely restricted their opportunities for integration on release. To many commentators, including offenders, it would be better to make communities more attractive rather than prisons less attractive to offenders, communities which are welcoming places, worthy of conformity and integration.

In terms of the factors that these respondents thought agencies should focus on to prevent youth crime in the future, the main one was offering young people better, more affordable leisure activities. Boredom and a lack of constructive alternatives in youth were of obvious concern to these young people. Even though not all the respondents started offending because of boredom, the majority still felt that giving young people more leisure and youth activities in their own communities was an important way of preventing the escalation of offending:

Maybe have more, you know, things for kids and that to do. Like up here, there's nothing really, not even a youth club or anything that I know. There's not, just nothing at all. So kids here just go down the town, you know, at weekends and drink bottles of cider and get themselves in trouble (Fiona, 30, new sample).

I think it has to go back further than the offending. I think it has to be - there has to be stuff put in before people get to the stage where they're offending. Like youth groups, all these kinda things seem to be dwindling away and I know a lot of it's about money but I think there has to be more options for young people, more activity based stuff that doesn't cost a lot of money (Theresa, 43, original sample, 2010). 
Drug or alcohol information and advice was recommended, but primarily by the original sample who were interviewed again 10 years later. With the benefit of hindsight, this older sample strongly suggested the need for more drug and alcohol education to deter young people from experimenting with such substances. Many mentioned that drugs were a major issue for young people, not only because they were illegal and therefore held more attraction, but also because they can easily be introduced into communities and easily available in prison. Some of the respondents I spoke to had never touched heroin until they were in prison. One respondent also suggested that not only can it take 9+ months to get onto a methadone programme, but it is also difficult at times to persuade doctors that young people might want to come off it, partly because doctors (and pharmacists) may benefit financially from prescribing methadone:

If [doctors] are gonna put them down the line of Methadone and things like that, let them know the pros and the cons, not just that it'll help you and you'll get better! They should tell you too: 'oh, you might be on this stuff when you're going to your grave'... They don't let you know the pros and the cons, they just tell you the good bits of it... I didn't think I'd still be sitting here today on Methadone, do you know what I mean? (Marie, 21, original sample, 2000).

Marie said this in her first interview in 2000. When interviewed ten years later, she said she was still on methadone, albeit on a slowly reducing amount.

Drugs are not usually an issue (in terms of addiction) when young people start offending, but substance misuse can rapidly become an issue during the course of an offending career, although methadone programmes often reduce the need for people to steal for money for drugs. But even though it is free, methadone has its problems. It isan issue just now in Scotland, given that in 2010 more than a third of those who died in drug-related incidents were on methadone, suggesting that they were combining it, whether or not prescribed, with other drugs of choice (National Records of Scotland, 2011). There has also been a 75 per cent increase in drug and alcohol related deaths in the last 10 years, and the dangers from drugs are more acute with the older user (i.e. those in their late $20 \mathrm{~s}$ and beyond, rather than adolescents), suggesting the possibility of offending careers extending into the late twenties and thirties because of drug misuse. For example, in Figure 1 below, we can see that this sample's self-reported age-crime curve shows a prolonged and uncertain pathway towards desistance, not the typical age-crime curve which peaks at 16, drops off sharply in the earlytwenties, and usually ends by the late-twenties. It is a longer, more 'zig-zag' path to desistance than it used to be and drug/alcohol misuse is undoubtedly a significant factor in this. 
Figure 1: Age-crime curve by self-reported offending status

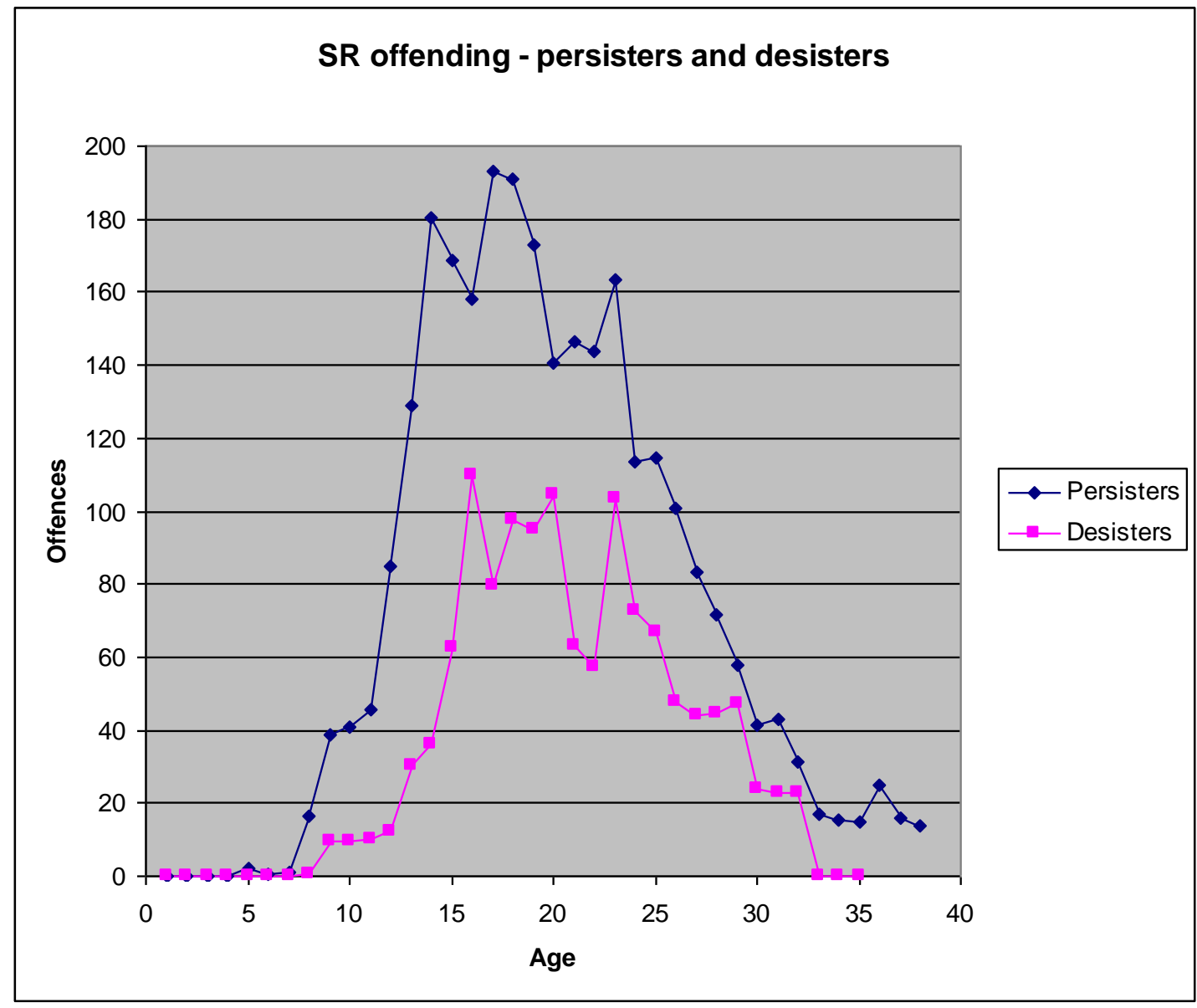

A further factor that this sample felt was important in encouraging desistance (and discouraging drug use) was the need to reduce unemployment, homelessness and poverty. However, unemployment and poverty were stressed primarily by the older respondents, more so the original sample after 10 years, whose criminal records were more of an issue than for the younger sample who were arguably less concerned with the politics or practicalities of poverty and unemployment. But they still understood that a sense of belonging or social recognition (Barry, 2006) was important, whether through the status of having their own tenancy or a legitimate income or through having constructive and trusted opportunities for meaningful employment in mainstream society rather than being marginalised or excluded.

Probation-type support was also deemed a major factor in helping young people to reduce or cease offending. Not only did these respondents strongly emphasise the need for one to one support as being the best means of encouraging desistance, but they also strongly recommended having workers who have previous experience of offending or drug use because they might be more street wise and empathic than workers who know little about life other than through textbooks:

It was great to talk to people like yourself who didn't talk down to you, they didn't judge you. They spoke to you like a normal person and they could relate to you (Bernadette, 34, old sample, 2010/11). 
I would like - you know what, I would like to be a worker that goes... round and tells people, look this is how it is, you know, like real life, not text book junkies, do you know what I mean, that have just read the book and they tell you that you're not rattling, but you're physically strung out to fuck. And they're saying: 'no you're fine'. No, I'm not, you know, I'm pure dying, my legs are fucking aching. 'No, you're fine'! (Emma, 26, new sample).

Despite social workers often being considered to have little first-hand experience of disadvantage, some respondents thought that such workers needed to be more committed to helping young people, and have a consistent presence. Indeed the Scottish Government in its recent review of reoffending in Scotland also acknowledges that workers need to be respectful and flexible in their dealings with offenders (Scottish Government, 2011). Equally, continuity and consistency of supervisor is invariably a concern to offenders under community-based orders, not least those lasting for prolonged periods, and yet workforce turnover and management can seldom allow for such consistency of contact. Barry (2000), Farrall (2002) and McNeill (2006), amongst others, have pointed to the need for meaningful, non-judgemental and proactive relationships between worker and client which are founded on continuity and consistency. The following quotation is, however, regrettably not unusual amongst respondents talking about social work:

I think there should be more - what's the word - like more interaction, more - well, you go in and they must think: 'I've got 10 people to see today', so they just rattle through it... and they're like that: 'oh, I've got another person coming in at half three'... Some people say to me, you have to open up. No, I don't have to open up. If I want to, I will. I've opened up to that many workers in my life, I can't be bothered meeting a new one to tell them my life story again... They should have like one worker that gets to know you and you can work with them and you can tell them things. But if you're getting passed from pillar to post. I'm not wanting to tell the [entire] social work department my life story (Emma, 26, new sample).

Earlier intervention in children's lives was seen as important by a minority of respondents, including giving talks in schools (possibly using ex-offenders as peer educators). But one respondent stressed that young people should not be criminalised by early intervention in their lives:

Stop jailing them and stop putting them in homes and messing with their heads when they're young... Instead of jailing them and damaging them in that way, actually give them a cuddle and a kiss or whatever. Nurture them properly (Nick, 38, original sample, 2010).

Finally, whilst many respondents suggested ways that policy makers and practitioners could help young people stop offending, they often qualified that by saying that the young person had to want to stop themselves: 
You've got to want to do it deep down in yourself... I don't think there's anything that people can do unless the person wants help (Harry, 36, original sample, 2010).

Nobody can help you stop, you've gotta just, you've gotta want to do it for yourself. See if you don't want to do it for yourself, you've got no hope.

However, this is not to argue that policy makers and practitioners can sit back and wait for it to happen, or necessarily that they can 'teach' young people to want to stop offending (e.g., through cognitive behavioural programmes or the deterrence of punishment). I have mentioned elsewhere my fear that the desistance process is becoming individualised, that young people are expected to, in effect, stop offending on their own, without outside help (Barry, 2012). They have got to be motivated but equally, they have got to have hope - hope of a better or even just a normal life, with at least some of the trappings that other people have in life. Yet, as MacDonald et al (2011: 150) point out, young people steadfastly refuse to believe that hope can come from anywhere other than from within themselves, despite the 'conditions of history, place and class [that] are critical in understanding the biographies' of offenders.

\section{Discussion and Conclusions}

Part of this study of desistance in Scotland asked offenders and ex-offenders to put themselves in the role of theorist, policy maker and practitioner, a role which they all took seriously and from which the preceding findings were generated. Contrary to many criminological studies of desistance, however, these respondents came from a wide age range (18-43) and the majority were 'ex-offenders' rather than 'would-be desisters'. They were also persistent, high tariff offenders in their youth and the majority had neutral or negative views of criminal justice disposals, even looking back after many years. Fines, community service and imprisonment in particular were seen as unreasonable, ineffective and often counterproductive. Probation was a disposal that all the respondents had experienced and the one that generated the most positive views of its past record and the most suggestions for its future sustainability in the eyes of offenders. The most significant message coming from these individuals about probation was that the personality of the worker, the subsequent relationship with the client and the need for continuity and consistency of approach were of far greater importance than the content of the programme per se.

These relational concerns about probation were also prevalent in respondents' views about policy and practice measures to reduce offending amongst young people in the future. Communication which is respectful, non-judgemental and constructive (i.e., forward thinking rather than backward thinking) was a key concern of these respondents for effective social work interventions to encourage and sustain desistance. Education about harmful substance misuse was also important as were leisure facilities to reduce boredom and therefore reduce re-offending. Employment and accommodation were also key to this ambition for normality and integration within mainstream society (bearing in mind the crucial age and stage at which offending is most likely to occur, in the liminal phase of the transition to adulthood). 
As mentioned earlier, many of the respondents in this study gave up crime in anticipation of something constructive happening in their lives rather than in response to something already having happened. This is a crucial distinction for policy makers in particular to make, not least when the desistance literature misleadingly implies that opportunities or turning points somehow magically materialise in the run up to, or during the process of, desistance. This sample seemed only to live in hope, with no real opportunities for change evident as an immediate incentive to forego the advantages of offending. And yet young offenders do eventually forego those advantages, albeit with difficulty, as Figure 1 above illustrates. Giordano et al (2002) suggest that desistance requires the offender to envision an appealing and conventional alternative identity through which he/she 'creatively and selectively draws upon elements of the environment in order to affect significant life changes' (ibid: 1003, emphasis added). This could be seen as somewhat simplistic when, in the UK at least, disadvantaged populations are marginalised, state benefits reduced and unemployment an impossible dream for young people. One would need to be particularly creative and selective to affect significant life changes in today's political and economic environment, irrespective of whether or not one has a criminal record. And yet criminologists and policy makers alike imply that desistance requires agency first and foremost, following which - with hope, a strategy and 'capital' - structural opportunities will materialise. This could not be further from the truth for many disadvantaged young people.

Inequality of income has, in the past, been argued to encourage crime amongst the relatively poor in our society. This article argues that inequality of opportunity could also encourage crime amongst the relatively marginalised in our society. Leonardsen (2003) argues that crime denotes a lack of belonging or obligation to the established community, but the findings from this study of desistance in Scotland suggest more than this, that crime epitomises a lack of recognition by the established community. Desistance by design should not just mean that offenders make a conscious effort to change but that the society into which they wish to integrate also makes a conscious effort to welcome them. Desistance is a twoway process and must be recognised as such.

\section{References}

Barry, M. (2000) "The mentor/monitor debate in criminal justice: "what works" for offenders', British Journal of Social Work, Vol. 30: 575-595.

Barry, M. (2006) Youth Offending in Transition: The search for social recognition, Abingdon: Routledge.

Barry, M. (2007) 'Youth offending and youth transitions: the power of capital in influencing change', Critical Criminology, 15: 185-198.

Barry, M. (2012) 'Desisters on Desistance', paper presented at the ESRC Desistance Seminar, September, Glasgow:University of Strathclyde. 
Burnett, R. (1992) The Dynamics of Recidivism, Oxford: Centre for Criminological Research.

Burnett, R. (2004) 'To reoffend or not to reoffend? The ambivalence of convicted property offenders', in S. Maruna and R. Immarigeon (eds) After Crime and Punishment: Pathways to offender reintegration, Cullompton: Willan.

Farrall, S. (2002) Rethinking What Works with Offenders, Cullompton: Willan.

Farrall, S. and Calverley, A. (2006) Understanding Desistance from Crime, Crime and Justice Series, London: Open University Press.

Gelsthorpe, L. (2007) 'Sentencing and gender' in R. Sheehan, G. McIvor and C. Trotter (eds) What Works with Women Offenders, Cullompton: Willan.

Giordano, P, Cernovich, S. and Rudolph, J. (2002) 'Gender, crime and desistance: Toward a theory of cognitive transformation', American Journal of Sociology, 107: 990-1064.

Gottfredson, M. R. and Hirschi, T. (1990) A General Theory of Crime, Stanford, CA: Stanford University Press.

Healy, D. (2010) The Dynamics of Desistance: Charting pathways through change, Cullompton: Willan.

Hirschi, T. (1969) Causes of Delinquency, Berkeley, CA: University of California Press.

Laub, J. and Sampson, R.J. (2003) Shared Beginnings, Divergent Lives: Delinquent boys to age 70, Cambridge, MA: Harvard University Press.

LeBel, T., Burnett, R., Maruna, S. and Bushway, S. (2008) 'The "Chicken and Egg" of Subjective and Social Factors in Desistance from Crime', European Journal of Criminology, Vol. 5 (2): 131-159.

Leonardsen, D. (2003) 'Crime in Japan - a lesson for criminological theory?' Selected papers from the 2003 British Criminology Conference, Bangor, June, British Society of Criminology, Vol. 6.

MacDonald, R., Webster, C., Shildrick, T. and Simpson, M. (2011) 'Paths of exclusion, inclusion and desistance: Understanding marginalised young people's criminal careers' in S. Farrall, M. Hough, S. Maruna and R. Sparks (eds) Escape Routes: Contemporary perspectives on life after punishment, Abingdon: Routledge.

McNeill, F. (2006) 'A desistance paradigm for offender management', Criminology and Criminal Justice, 6: 39-62. 
McNeill, F., Farrall, S., Lightowler, C. and Maruna, S. (2012) How and why people stop offending: Discovering desistance, Insights No. 15, Glasgow: IRISS.

Moloney, M., MacKenzie, K., Hunt, G. and Joe-Laidler, K. (2009) 'The path and promise of fatherhood for gang members', British Journal of Criminology, 49: 305-325.

Munro, M. and McNeill, F. (2010) 'Fines, community sanctions and measures in Scotland' in H. Croall, G. Mooney and M. Munro (eds) Criminal Justice in Scotland, Cullompton: Willan.

National Records of Scotland (2011) Drug-related Deaths in Scotland in 2010, Edinburgh: National Records of Scotland.

Nellis, M. (2013) 'Electronic Monitoring and Surveillance-based Compliance', in P. Raynor and P. Ugwudike (eds) What Works in Offender Compliance? London: Routledge.

Paternoster, R. and Bushway, S.(2009) 'Desistance and the "feared self": Toward an identity theory ofcriminal desistance, Journal of Criminal Law \& Criminology, Vol. 99, No. 4, 11031156.

Rex, S. (1999) 'Desistance from offending: experiences of probation', Howard Journal of Criminal Justice, 38 (4): 366-383.

Sampson, R.J. and Laub, J. (1993) Crime in the Making: Pathways and turning points through life, Cambridge, MA: Harvard University Press.

Scottish Government (2011) What Works to Reduce Reoffending: A Summary of the Evidence, Edinburgh: Scottish Government.

Scottish Government (2012) Redesigning the Community Justice System: A Consultation on Proposals, Edinburgh: Scottish Government, http://www.scotland.gov.uk/Publications/2012/12/7292

Shildrick, T., MacDonald, R., Webster, C. and Garthwaite, K (2012) Poverty and Insecurity: Life in low-pay, no-pay Britain, Bristol: Policy Press.

Shover, N. (1996) Great Pretenders: Pursuits and Careers of Persistent Thieves, Boulder, CO: Westview Press.

Uggen, C. (2000) 'Work as a turning point in the life course of criminals: A duration model of age, employment and recidivism', American Sociological Review, 65: 529-46.

Weaver, B. (2011) Co-Producing Community Justice: The Transformative Potential of Personalisation for Penal Sanctions,British Journal of Social Work, 41 (6): 1038-1057. 
Weaver, B. (2012) 'The relational context of desistance: Some implications and opportunities for social policy’, Social Policy and Administration, Vol. 46, No. 4: 395-412.

Weaver, B. and Armstrong, S. (2011) 'User views of punishment - The dynamics of community-based punishment: Insider views from the Outside, Research report No. 03/2011, Glasgow: Scottish Centre for Crime and Justice Research, published online at www.sccjr.ac.uk. 